\title{
DETECTION OF PARTIAL ROTOR BAR RUPTURE OF A CAGE INDUCTION MOTOR USING LEAST SQUARE SUPPORT VECTOR MACHINE APPROACH
}

\author{
M'hamed BIRAME ${ }^{1}$, Sid Ahmed BESSEDIK ${ }^{2}$, Mohamed Fouad BENKHORIS ${ }^{3}$ \\ ${ }^{1}$ Ledmased Laboratory, University of Laghouat, 03000, Algeria \\ ${ }^{2}$ (LACoSERE) University of Laghouat, 03000, Algeria \\ ${ }^{3}$ IREENA, Saint Nazaire, Polytech'Nantes, France \\ bir_moh@yahoo.fr, s.bessedik@lagh-univ.dz, mohamed-fouad.benkhoris@ polytech.univ-nantes.fr
}

\begin{abstract}
Squirrel cage induction motors suffer from numerous faults, for example cracks in the rotor bars. This paper aims to present a novel algorithm based on Least Squares Support Vector Machine (LS-SVM) for detection partial rupture rotor bar of the squirrel cage asynchronous machine. The stator current spectral analysis based on FFT method is applied in order to extract the fault frequencies related to rotor bar partial rupture. Afterward the LS-SVM approach is established as monitoring system to detect the degree of rupture rotor bar. The training and testing data sets used are derived from the spectral analysis of one stator phase current, containing information about characteristic harmonics related to the partial rupture rotor bar. Satisfactory and more accurate results are obtained by applying LS-SVM to fault diagnosis of rotor bar.
\end{abstract}

Keywords: (Fault diagnosis, partial rupture rotor bar, spectral analysis, least square support vector machine (LS-SVM)),

\section{INTRODUCTION}

Induction motors are the mainstay for every industry. However like any other machine, they will eventually fail because of heavy duty cycles, poor working environment, installation and manufacturing factors, etc. With escalating demands for reliability and efficiency, the field of fault diagnosis in induction motors is gaining importance [1-3]. The diagnosis and oversight of a device are generally passed through the knowledge of his healthy behaviour, total control of the various modes of operation is then essential when considering an advanced monitoring of the process

For this purpose, their maintenance and their diagnosis have become an economic issue. Therefore, it is recommended to detect faults early in order to remedy them in the shortest possible time to minimize the effects on the electrical installation or on the machine itself. Broadly, an induction motor can develop either internal fault or external fault. With reference to the origin, a fault may be mechanical or electrical. Fault can be classified as stator fault or rotor fault depending on the location of the fault. Faults associated with the moving parts like bearing and cooling faults are categorized as rotor faults [1-2].

The detection of broken rotor bars in induction motor is very important issue. Therefore, several diagnostic approaches are employed. Those methods are based mainly on the signals spectrum analysis utilizing Fast Fourier
Transform (FFT), in particular motor current signature analysis (MSCA) [2], [3], [4] or internal signals from closed-loop control structure [6]. [2$3]$.Over the recent years, there has been increasing efforts dedicated in establishing AI based models to predict real-world time-dependent data. Various AI approaches such as the Artificial Neural Network (ANN), Adaptive Network based Fuzzy Inference System (ANFIS), Support Vector Machine (SVM), and Least Squares Support Vector Machine (LSSVM) approaches have been applied to cope with time series prediction in various domains [4-6]. Support vector machines have been utilized as a popular algorithm realized from the machine learning [7]. $L S-S V M$ is a modification of the original $S V M$ where the resulting optimization problem has half the number of parameters and the model is optimized by solving a linear system of equations instead of a quadratic programming [7-8].

In this paper, LS-SVM approach is proposed for fault diagnosis and estimation of the partial rupture rotor bar of the squirrel cage asynchronous machine using information provided by the frequency analysis of the stator current phase.

The rest of this paper is structured as follows. Sections 2 give a short presentation of multiwinding model of squirrel-cage induction motor. Section 3 describes the LS-SVM approach followed by the proposed methodology in section 4 . Section 5 is devoted to simulation results and conclusion of this study is conducted in the last section. 


\section{MULTI-WINDING MODEL OF SQUIRREL-CAGE INDUCTION MOTOR}

The development of a diagnostic procedure, based on analytical models for asynchronous machines, requires the synthesis of a model able to take into account its structure and to account for the transient behaviour of the latter. To do this, we must move towards the multi-winding model to be able to individually represent the rotor bars for a description better suited to defects. The modelling described in this section is intended to represent the short-circuit bars and rings individually for in asynchronous squirrel cage motors [2].

\subsection{Electrics equations}

Figure. 1 shows the equivalent electrical circuit of a rotor mesh, where the rotor bars and the shortcircuit ring portions are represented by their corresponding resistances and leakage inductances.

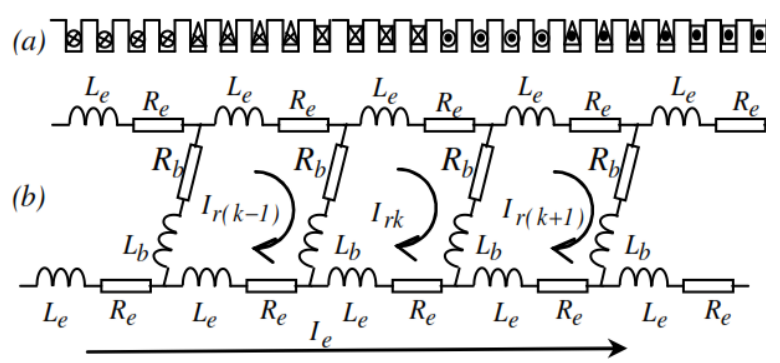

Fig. 1 Equivalent electric circuit of the rotor cage

With reference to Figure.1, the equations for stator and rotor voltages meshes will be:

$$
[\mathrm{V}]=[\mathrm{R}][\mathrm{I}]+\frac{\mathrm{d}([\mathrm{L}] \cdot[\mathrm{I}])}{\mathrm{dt}}
$$

The matrix of voltage and currant respectively as flows by:

$$
[\mathrm{V}]=\left[\begin{array}{l}
{\left[\mathrm{V}_{\mathrm{s}}\right]} \\
{\left[\mathrm{V}_{\mathrm{r}}\right]}
\end{array}\right],[\mathrm{I}]=\left[\begin{array}{l}
{\left[\mathrm{I}_{\mathrm{S}}\right]} \\
{\left[\mathrm{I}_{\mathrm{r}}\right]}
\end{array}\right]
$$

With :

$$
\begin{aligned}
& {\left[V_{s}\right]=\left[V_{s a} V_{s b} V_{s c}\right]} \\
& {\left[V_{r}\right]=\left[\begin{array}{lllll}
V_{r 1} V_{r 2} & \ldots & \ldots & V_{r N_{b}} V_{r e}
\end{array}\right]^{t}} \\
& {\left[I_{s}\right]=\left[I_{s a} I_{s b} I_{s c}\right]^{t}} \\
& {\left[I_{r}\right]=\left[\begin{array}{llll}
I_{r 1} I_{r 2} & \ldots & \ldots & I_{r k b} I_{e}
\end{array}\right]^{t}}
\end{aligned}
$$

The stator resistance matrix is given by:

$$
\left[R_{S}\right]=\left[\begin{array}{ccc}
R s & 0 & 0 \\
0 & R s & 0 \\
0 & 0 & R s
\end{array}\right]
$$

The rotor resistance matrix is given by:

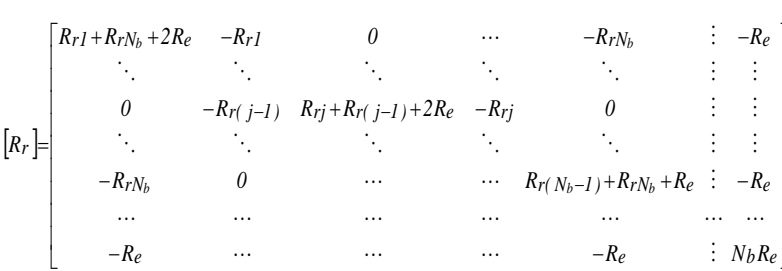

(4)

The mutual inductance matrix between stator phases and rotor mesh is following by:

$\left[\mathrm{L}_{\mathrm{sr}}\right]=\left[\begin{array}{cccccc}\mathrm{L}_{\mathrm{ar} 1} & \mathrm{~L}_{\mathrm{ar} 2} & \ldots \ldots \ldots \mathrm{L}_{\mathrm{ar}\left(\mathrm{N}_{\mathrm{b}}-1\right)} & \mathrm{L}_{\mathrm{arN}_{\mathrm{b}}} & 0 \\ \mathrm{~L}_{\mathrm{ba}} & \mathrm{L}_{\mathrm{b}} & \ldots \ldots \ldots . . \mathrm{L}_{\mathrm{br}\left(\mathrm{N}_{\mathrm{b}}-1\right)} & \mathrm{L}_{\mathrm{brN}_{\mathrm{b}}} & 0 \\ \mathrm{~L}_{\mathrm{ca}} & \mathrm{L}_{\mathrm{cb}} & \ldots \ldots \ldots \ldots \mathrm{L}_{\mathrm{cr}\left(\mathrm{N}_{\mathrm{b}}-1\right)} & \mathrm{L}_{\mathrm{crN}_{\mathrm{b}}} & 0\end{array}\right]$

The matrix of inductances of stator phases:

$\left[\mathrm{L}_{\mathrm{ss}}\right]=\left[\begin{array}{ccc}\mathrm{L}_{\mathrm{a}} & \mathrm{L}_{a b} & \mathrm{~L}_{a c} \\ \mathrm{~L}_{\mathrm{ba}} & \mathrm{L}_{\mathrm{b}} & \mathrm{L}_{\mathrm{bc}} \\ \mathrm{L}_{\mathrm{ca}} & \mathrm{L}_{\mathrm{cb}} & c\end{array}\right]$

The matrix of inductances of rotor expressed by the relationship (7)

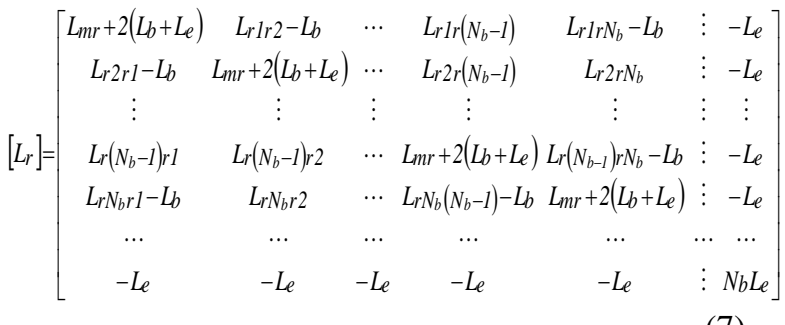

\subsection{Mechanical equation}

Depending on the application to which the motor is designated, it is possible to define the mechanical equation of the associated motion by:

$$
\mathrm{J} \frac{\mathrm{d} \Omega_{\mathrm{r}}}{\mathrm{dt}}+\mathrm{f}_{\mathrm{v}} \Omega_{\mathrm{r}}=\mathrm{C}_{\mathrm{e}}-\mathrm{C}_{\mathrm{r}}
$$

\section{a. Case of the crack of (n) rotor bars:}

In this study, the broken rotor bar is modelled by increasing the resistance of the broken bar. The procedure consists in adding to the matrix of rotor resistances $\left[R_{r}\right]$ a new matrix $\left[R_{d}\right]$. In the event that the fault concerns a bar $k$, the matrix $\left[\mathrm{R}_{\mathrm{d}}\right]$ is written as follows:

$\left[R_{d}\right]=\left[\begin{array}{clccc}0 & 0 & 0 & \cdots & 0 \\ \vdots & 0 & \cdots & \cdots & 0 \\ \vdots & R_{k, k} & R_{k, k+1} & 0 & \vdots \\ 0 & R_{k+1, k} & R_{k+1, k+1} & \vdots & \vdots \\ 0 & \cdots & \cdots & 0 & 0\end{array}\right]$

With;

$$
\begin{aligned}
& R_{k, k}=R_{k+1, k+1}=(M+1) \times R_{b}+2 \times R_{e} \\
& R_{k+1, k}=R_{k, k+1}=(-M) \times R_{b}
\end{aligned}
$$

In case of the broken bar, the value of the resistance $R_{b}$ is multiplied by a factor of $M=7 \times 10^{3}$.

So, the squirrel cage resistance matrix, taking into account the defect, is defined as follows:

$\left[R_{R d}\right]=\left[R_{R}\right]+\left[R_{d}\right]$

In order to modelling a Partial Rupture (PR) rotor bar, the resistance $R_{b}$ is multiplied by a factor 
$M$ varied between 70 and 700 . This factor can be rewrite as $M=700 * M^{\prime}$, where the new factor $M^{\prime}$ ' take the values in percentage $10 \%, 20 \% \ldots 100 \%$. The maximum value of $M$ is 700 for $M^{\prime}$ equal to $100 \%$.

\section{LEAST SQUARES SUPPORT VECTOR MACHINES}

A short description of LS-SVM is presented in this section while a detailed theatrical and description are given in the references [8-12]. The aim of LS-SVM regression problem for given dataset $\left\{x_{i}, y_{i}\right\}_{i=1}^{N}$, is to approximation a model of the form:

$$
y=w^{T} \phi(x)+b
$$

where $w$ is the weight vector, $\phi$ is the nonlinear function that maps the input space to a highdimension feature space and performs linear regression, and $b$ represent the bias term.

In the case of function estimation task, the Structural Risk Minimization (SRM) principle is introduced, and the optimization problem is used to formulate the Eq.(14), where $\gamma$ indicate the regularization parameter to calculate the trade-off between the smoothness of the estimation function and training error minimization, and $e_{i}$ is the error between the desired and the actual output.

$$
\begin{aligned}
& \min j(w, e)=\frac{1}{2} w^{T} w+\frac{1}{2} \gamma \sum_{i=1}^{N} e_{i}^{2} \\
& \text { s.t. } y_{i}=w^{T} \phi\left(x_{i}\right)+b+e_{i} \quad i=1,2 \ldots ., N
\end{aligned}
$$

Lagrange Multiplier optimal programming method is applied to solve Eq.(14) and to derive solutions $w$ and $e_{i}$. The method considers objective and constraint terms simultaneously. Lagrange function $L$ is shown as Eq.(15).

$$
L(w, b, e, \alpha)=\frac{1}{2}\|w\|^{2}+\gamma \sum_{i=1}^{N} e_{i}^{2}-\sum_{i=1}^{N} \alpha_{i}\left\{w^{T} \phi\left(x_{i}\right)+b+e_{i}-y_{i}\right\}
$$

where $\alpha_{i}$ are Lagrange multipliers.

The solution of Eq.(15) can be found by partially differentiating with respect to $w, b, e_{i}$ and $\alpha_{i}$ :

$$
\left\{\begin{array}{l}
\frac{\partial L}{\partial w}=0 \rightarrow w=\sum_{i=1}^{N} \alpha_{i} \phi\left(x_{i}\right) \\
\frac{\partial L}{\partial b}=0 \rightarrow \sum_{i=1}^{N} \alpha_{i}=0 \\
\frac{\partial L}{\partial e_{i}}=0 \rightarrow \alpha_{i}=\gamma e_{i} \quad i=1,2 \ldots ., N \\
\frac{\partial L}{\partial \alpha_{i}}=0 \rightarrow w^{T} \phi\left(x_{i}\right)+b+e_{i}-y_{i}=\gamma e_{i} \quad i=1,2 \ldots ., N
\end{array}\right.
$$

The solution yields after elimination of $w$ and $e_{i}$,

$$
\left[\begin{array}{rr}
0 & 1 \\
1 & k+\frac{1}{\gamma} I
\end{array}\right]\left[\begin{array}{l}
b \\
\alpha
\end{array}\right]=\left[\begin{array}{l}
0 \\
y
\end{array}\right]
$$

with $\alpha=\left[\alpha_{1}, \alpha_{2}, \ldots, \alpha_{N}\right]^{\mathrm{T}}, y=\left[y_{1}, y_{2}, \ldots, y_{N}\right]^{\mathrm{T}}$ and $1=[1,1, \ldots, 1]^{\mathrm{T}}$. Here, $I$ is an $N \times N$ identity matrix, and $k \in \mathrm{R}^{N \times N}$ is the kernel matrix defined by:

$$
k\left(x_{i}, x_{j}\right)=\phi\left(x_{i}\right)^{T} \phi\left(x_{j}\right)
$$

The resulting LS-SVM model for function estimation can be expressed as:

$$
y=\sum_{i=1}^{N} \alpha_{i} k\left(x_{i}, x\right)+b
$$

The basic features of a kernel function are derived from Mercer's theorem. All function satisfies Mercer's condition is defined as kernel function. Typical examples of the kernel function are radial basis function (RBF) kernel, sigmoid kernel and polynomial kernel (Poly) [12].

The RBF function is widely used in different fields as kernel function. In this paper, RBF function is also selected for the proposed LS-SVM detected approach as suitable kernel function, whose formulation is defined as follows:

$K\left(x_{i}, x_{j}\right)=\exp \left(-\frac{\left\|x_{i}-x_{j}\right\|^{2}}{\sigma^{2}}\right)$

where $\sigma^{2}$ is the squared variance of the RBF function.

\section{METHODOLOGY}

A database composed of inputs/output data sets has been used to train and to the proposed LS-SVM detected approach. The data sets inputs/outputs are collected through simulations in Matlab environment.

In this study, we followed the same steps proposed by previous work [13-15], we therefore assured that:

- The frequencies of the characteristic harmonics related to the Partial Rupture (PR) rotor bar vary with the variation of the speed.

- The variation of the load, for the same degree of the partial rupture bar, influences both on the amplitude of the fundamental and on the amplitude of the harmonics characterizing the defect.

- The variation of the severity partial rupture bar for a given load influences the characteristic harmonics of the defect.

The training set consists of 30 vectors were derived from the simulation cage induction model using stator current spectral analysis. The LS-SVM monitoring system was tested using different 19 simulation vectors. 
The input variable $A_{l}$ represents the values of the ratios of the amplitude of the first fault characteristic harmonic related to the PR rotor bar $f_{b 1}$ by the amplitude of the fundamental harmonic: (Al=Ampfbl/Ampf), whereas the variable $A_{2}$ represents those of the second fault characteristic harmonic: $(A 2=A m p f b 2 / A m p f)[15]$.

The output variable takes indicators values defining the degree of partial rupture in percentage of one and two bars under several load value.

\section{RESULTS AND DISCUSSION}

As mentioned in previous section, the stator current spectral analysis based on Fast Fourier Transform (FFT) method is used for building a database needed for LS-SVM detected approach.

All the simulations presented in this section were performed using the machine parameters given in table 1.

Figure 2 illustrates the stator current (Isa) of a squirrel cage induction motor for healthy and faulty with one broken bar at time 2 [s], and two broken bars at time $3[\mathrm{~s}]$ under load of $T_{L}=4$ N.m.

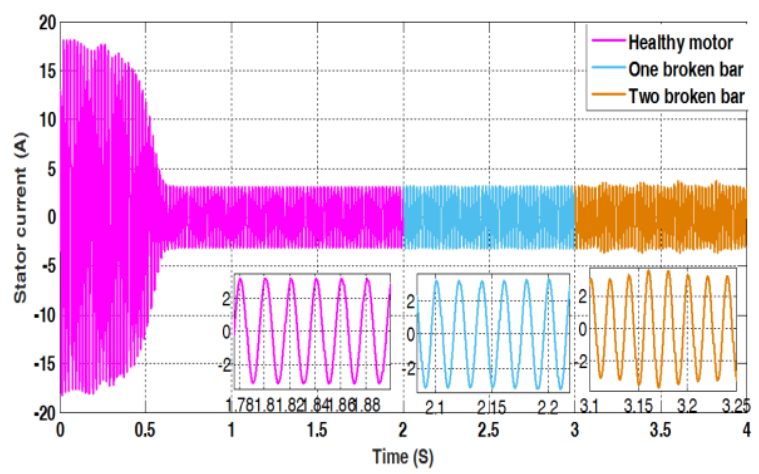

Fig. 2 Stator current for healthy motor, one broken bar and two broken bars

According to the shape of the stator current of figure 2, it is difficult to observe the effect of the broken bars on the stator current, indeed the amplitude current has only a low modulation which making this analysis imprecise.

Figure 3 shows the spectrum of the stator current for healthy motor, one broken bar and two broken bars.

From figure 3 , it is easy to detect and classify the characteristic harmonics related to the broken rotor bar. As seen in the same figure these harmonics were appear on either side of the fundamental harmonic at frequencies:

$$
f_{b 1,2}=f_{s}(1 \pm 2 k s), k=1,2
$$

where $f_{s}$ of $50 \mathrm{~Hz}, s$ and $k$ represents respectively the fundamental frequency, the slip the number of rotor bars.

Figure 4 illustrate the degree in percentage of Partial Rupture (PR) of one rotor bar at load of $T_{L}=$ 4N.m. It can be noted that there is a very slight difference amplitude value of 0.08 between PR of

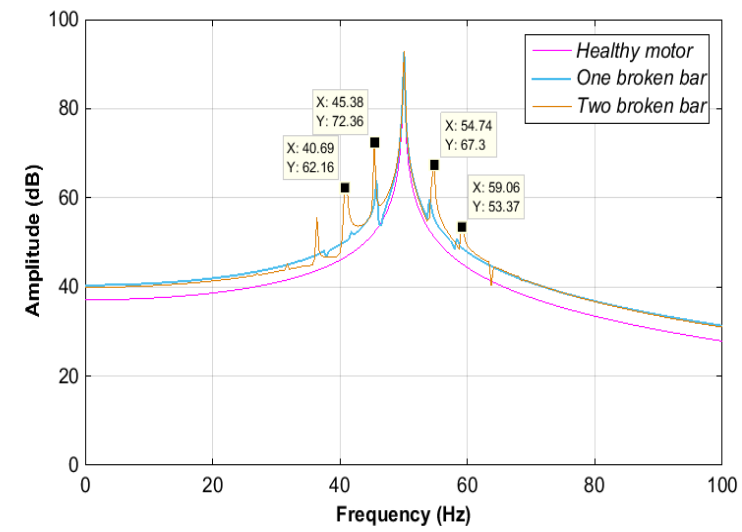

Fig. 3 Spectrum of the stator current for healthy motor, one broken bar and two broken bars

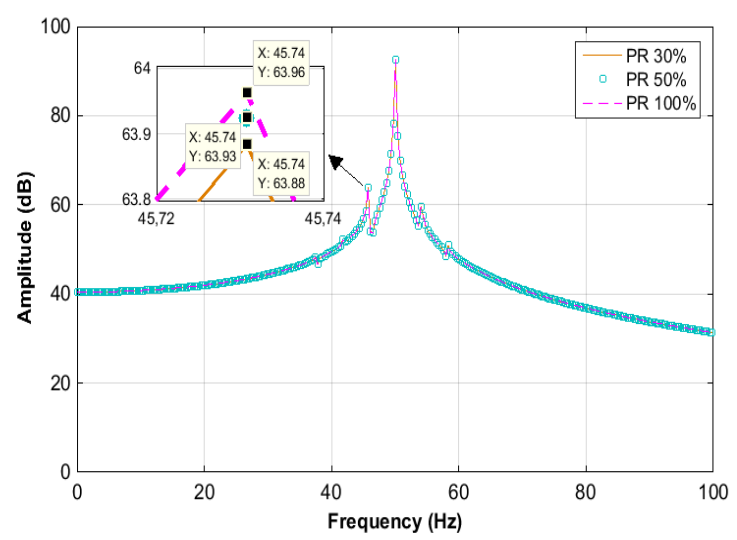

Fig. 4 Partial rupture in percentages of one bar of $30 \%$, $50 \%$ and $100 \%$

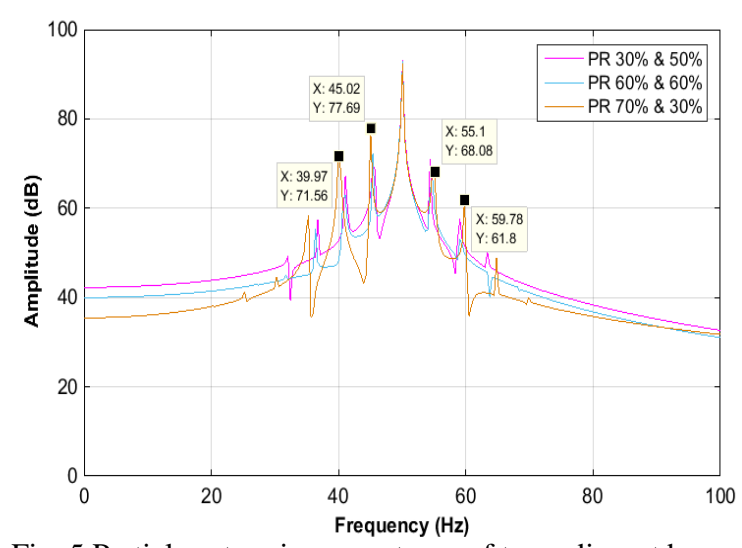

Fig. 5 Partial rupture in percentages of two adjacent bars under load of $T_{L}=4 \mathrm{~N} . \mathrm{m}$.

$30 \%$ and of $100 \%$. However, for more than one bar the degree of PR has a significant influence on the amplitude value of the faults harmonic. This analysis is illustrated in figure 5, which simulate PR in percentage simultaneously (differently and similarly) of two adjacent bars with values of $30 \%$ $\& 50 \%, 60 \% \& 60 \%$ and $70 \% \& 30 \%$.

The database of input variables $A 1$ and $A 2$ provided by stator current spectral analysis was carefully determined. The output variable takes four values (indicators) describing the degree of partial rupture in percentage of one and two bars under different load value: 
- 0.0: Indicate healthy motor (this case is not used for training and testing LS-SVM monitoring system).

- $\quad[0.2,0.4,0.6$ and 1.0]: Partial Rupture (PR) indicator of one rotor bar varying between $20 \%$ and $100 \%$.

- $[0.22,044,0.66$ and 1.1]: PR indicator of two bars varying similarly with the same value for each bar between $20 \%$ and $100 \%$.

- $[0.12 \sim 0.97]:$ PR indicator of two bars varying differently with the different value for each bar between $10 \% \& 20 \%$ and $90 \% \& 70 \%$.

In this paper, the parameters of LS-SVM approach have been selected after several tests. Therefore, the parameters adopted for this study are: $\gamma=1 \mathrm{e}+05$ and $\sigma^{2}=1 \mathrm{e}-05$.

In order to achieve good performance, all data for training and testing LS-SVM approach are randomly selected. The simulation results for LSSVM partial rupture rotor bar detection are shown in figures 6 and 7, in which 30 patterns/vectors are selected randomly to train the monitoring LS-SVM model and other 19 vectors are used to test its performance.

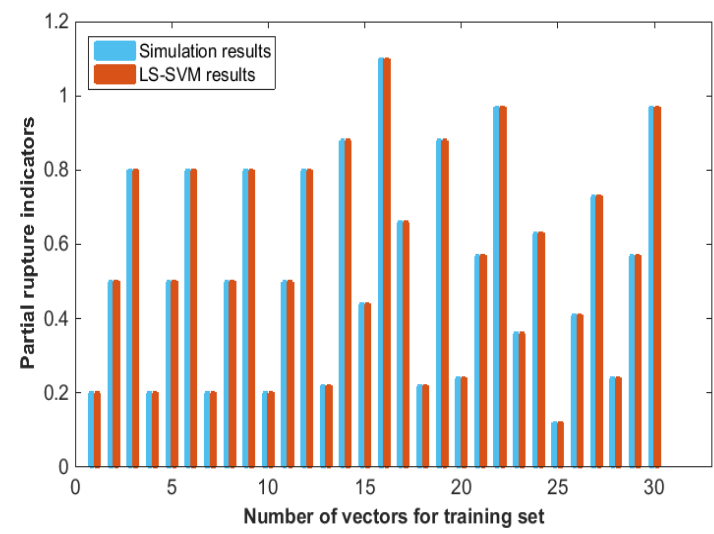

Fig. 6 Variation of PR indicator according to vector number for the training set

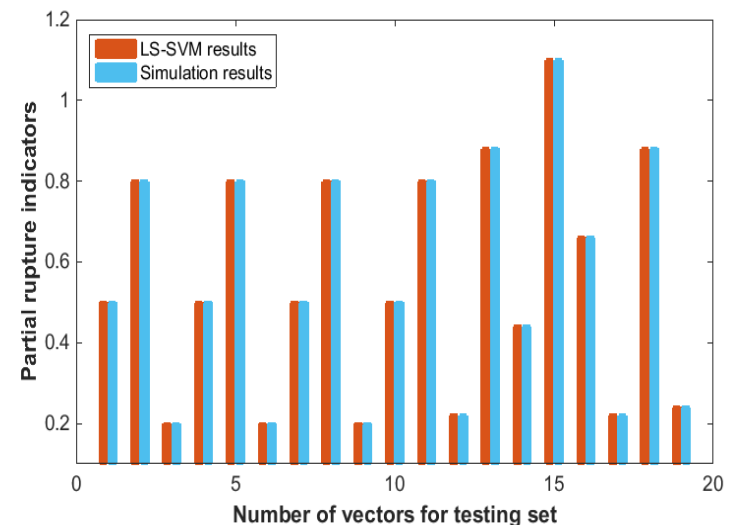

Fig. 7 Variation of PR indicator according to vector number for the testing set

Figures 6 and 7 show a very good adaptation of the LS-SVM results to the simulation results used respectively for the training and testing stage.

Noting also that the LS-SVM monitoring system has a very smaller Absolute Error (AE) for training and testing set with $1.0633 \mathrm{e}-04$ and 7.9820e-05 respectively. This model can therefore be considered as a tool of high efficiency in the field of diagnosis of degree of partial rupture rotor bar of cage inductor motor.

In addition, figure 8 and 9 illustrate the variation of the absolute error for training and testing stages. It is clearly that the errors corresponding to each stage are very low. The higher values of absolute error can be noted is of $1.6730 \mathrm{e}-05$ for testing stage.

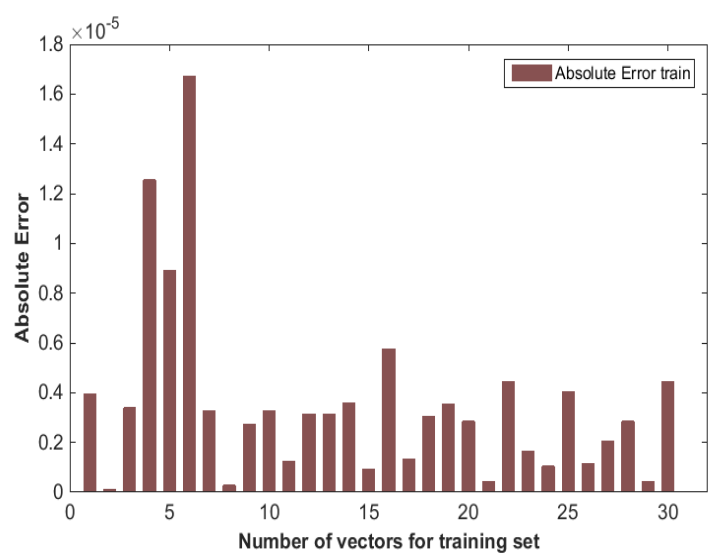

Fig. 8 Variation of absolute error according to vector number for the training set

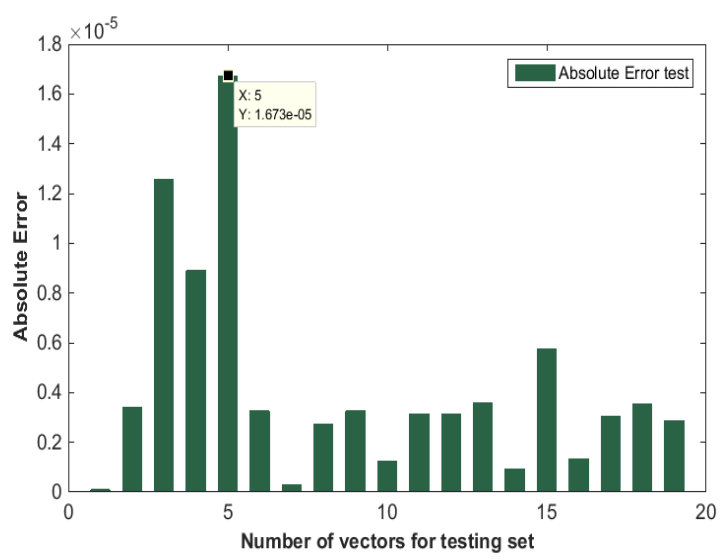

Fig. 9 Variation of absolute error according to vector number for the testing set.

Table 1: Machine parameters

\begin{tabular}{|l|l|}
\hline value & parameters \\
\hline $\mathrm{Rs}=2.89[\Omega]$ & Strength of a stator phase \\
\hline $\mathrm{P}=2$ & Number of pole pairs \\
\hline $\mathrm{J}=0.007[\mathrm{Kg} \cdot \mathrm{m} 2]$ & Moment of inertia \\
\hline $\mathrm{Nr}=28$ & Number of rotor bars \\
\hline $\mathrm{Ns}=464$ & Number of turns \\
\hline $\mathrm{Ls}=0.341[\mathrm{H}]$ & Stator inductance \\
\hline $\mathrm{Lr}=0.344[\mathrm{H}]$ & Rotor inductance \\
\hline $\mathrm{Un}: 220 / 380[\mathrm{~V}]$ & Nominal voltage \\
\hline $\mathrm{In}: 4,3 / 2,5[\mathrm{~A}]$ & Rated current \\
\hline $\mathrm{Nr}=1425[\mathrm{tr} / \mathrm{mn}]$ & Rated speed \\
\hline $\mathrm{Pn}=1.1[\mathrm{~kW}]$. & Nominal power \\
\hline $\mathrm{T}_{L}=7[\mathrm{~N} \cdot \mathrm{m}]$ & Rated torque \\
\hline
\end{tabular}




\section{CONCLUSION}

In this research paper, an algorithm based on LS-SVM has been considered as monitoring system to diagnosis of rotor defects in squirrel cage asynchronous machine, particularly the partial rupture rotor bar. The LS-SVM based on the introduction of a database which based on the information derived from the spectral analysis of the stator current of the machine. This database of inputs/outputs served to train the LS-SVM method. Once the training stage has been completed, a test is carried out in order to evaluate its performance. The obtained results demonstrate that the LS-SVM can successfully be used for detection the degree of partial rupture rotor bar. The proposed method could also be applied with higher accuracy in various types of faults appear in induction motor.

\section{REFERENCES}

1. Singh GK, Al Kazzaz SAS. Induction machine drive condition monitoring and diagnostic research-a survey. Electric Power Systems Research. 2003; 64: 145-158. https://doi.org/10.1016/S03787796(02)00172-4

2. Sin ML, Soong WL, Ertugrul N. Induction machine on-line condition monitoring and fault diagnosis a survey, AUPEC2003, Australasian Universities Power Engineering Conference, Christchurch, New Zealand. 2003:1-6.

3. Bhowmik SP, Pradhan S, Prakash M. Fault diagnostic and monitoring methods of induction motor: a review. International Journal of Applied Control, Electrical and Electronics Engineering. (IJACEEE). 2013; 1(1).

4. Bonnet AH, Soukup GC. Cause and analysis of stator and rotor failures in three phase squirrel cage induction motors. IEEE Transactions on Industry Application. 1992; 28(4)::921-937.

5. Shi ZJ, Li G. Fine tuning support vector machines for short-term wind speed forecasting. Energy Conversion and Management. 2011;52(4):19901998.https://doi.org/10.1016/j.enconman.2010.11.007

6. Yan W, Qiu H, Xue Y. Gaussian process for longterm time-series forecasting. Proceedings of the International Joint Conference on Neural Networks (IJCNN '09). 2009: 3420-3427.

7. Melin P, Soto J, Castillo O, Soria J. A new approach for time series prediction using ensembles of ANFIS models. Expert Systems with Applications. 2012; 39(3):3494-3506.

https://doi.org/10.1016/j.eswa.2011.09.040

8. Suykens J, Gestel JV, Brabanter JD, Moor BD. Vandewalle J. Least Square Support Vector Machines. World Scientific Publishers, Singapore, 2002.

9. Christianini N, Taylor J. Support vector machine and other kernel learning methods. London: Cambridge University Press, 2003.

10. Birame M, Taibi D, Bessedik SA, Benkhoris MF. Least square support vectors machines approach to diagnosis of stator winding short circuit fault in induction motor. Diagnostyka. 2020; 21(4):35-41. https://doi.org/10.29354/diag/130283

11. Bessedik SA, Hadi H. Prediction of flashover voltage of insulators using least squares support vector machine with particle swarm optimisation. Electric Power Systems Research. 2013;104:87-92. https://doi.org/10.1016/j.epsr.2013.06.013

12. Mahdjoubi A, Zegnini B, Belkheiri M, Prediction of critical flashover voltage of polluted Insulators under $\mathrm{sec}$ and rain conditions using least squares support vector machines (LS-SVM). Diagnostyka, 2019;20(1):49-54 https://doi.org/10.29354/diag/99854

13. Bensaoucha S, Bessedik S A,Ameur A and Teta A, Induction motors broken rotor bars detection using RPVM and neural network. COMPEL - The international journal for computation and mathematics in electrical and electronic engineering. 2019;38(2):595:615. https://doi.org/10.1108/COMPEL-06-2018-0256

14. Bensaoucha S, Ameur A, Bessedik S A and Teta A,. Comparative Investigation of Broken Bar Fault Detectability in Induction Motor Through FFT and MUSIC Techniques. International Conference on Communications and Electrical Engineering (ICCEE). IEEE. 2018: 1-5.

15. Laribi Souad. Use of Neuro-fuzzy technique in diagnosis of rotor faults of cage induction motor. 5th International Conference on Electrical Engineering (ICEE-B). Boumerdes, Algeria, 2017.

Received 2020-06-12

Accepted 2021-02-03

Available online 2021-02-04

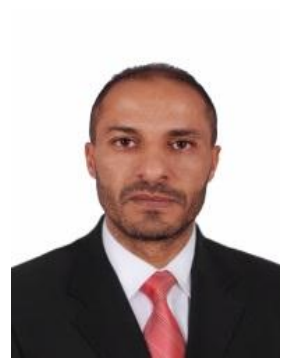

M'hamed BIRAME In 2005 he graduated (Magiter) with distinction at the Department of Electrical Engineering of the Faculty of Technology at Technical University in Batna. He defended his $P h D$ in the field of Power Electronics in 2015; his thesis title was "Control for speed sensorless direct torque control (DTC) applied to a variable synchronous reluctance machine (SRM) use of artificial intelligence techniques". Since 2005 he is working as Assistant Professor at Electrical Engineering Department. Laghouat University (Algeria). He is a member of the research group in LEDMASED Laboratory. His main research area includes Modeling of Electrical Machines, Electrical Drives Control, Power Electronics.

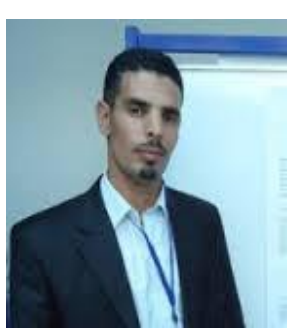

Sid Ahmed BESSEDIK received the Dipl. Ing. degrees in electrical engineering from the Univ-ersity Ibn Khaldoun Tiaret, Algeria in 2004 and Dipl. Magister in High Voltage from the University of Sciences and Technology of Oran (USTO) Algeria in 2008. Since 2010 he joined the University Amar Telidji Laghouat Algeria as assistant professor and researcher at the LACoSER laboratory. His main research interests include high voltage insulation, electromagnetic interference, fault diagnosis of induction motors, optimization methods and artificial intelligence techniques. 


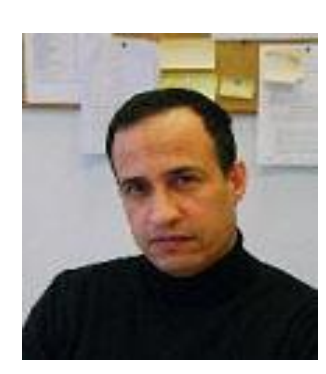

Mohamed Fouad

BENKHORIS He has studied

at Ecole Nationale

Polytechnique d'Alger

(ENPA), Algeria, and received

the Engineer degree in

electrical engineering (1986).

In 1991 he obtained his PHD

degree in electrical engineering

at INP Lorraine (France) and

the "HDR" (Habilitation à diriger des recherches) in

March 2004. From 1991, he is a Professor at the

Departement of Electrical Engineering, of

Polytech'Nantes, France. Since 2006 he is Professor at Polytech'Nantes, France. He makes research activities at the laboratrory: "Institut de Recherche en Electronique et Electrotechnique de Nantes Atlantique"(IREENA) Saint Nazaire. His fields of interest are: dynamical modelling, simulation and control of electrical drives and especially multi-phase drive, multi-converters systems and embarked network. 